\title{
Finite element analysis and structure improvement of CNC grinding machine lathe bed
}

\author{
Jinwei Fan, Qi Lva , Haohao Tao and Kaikai Liu \\ School of beijing University of technology, BeingJing 100024, China; \\ a18805488915@163.com
}

Keywords: CNC grinding machine, lathe bed, finite element analysis, modal analysis, improved structure.

\begin{abstract}
CNC grinding machine is the most commonly used finishing machine, lathe bed is the foundation of the machine tool key parts, as well as the guarantee for the machine tool dynamic stiffness. Taking a CNC grinding machine lathe bed as the research object, using Pro/E software to create the geometry model, and using finite element software ANSYS Workbench of simplified lathe bed for modal analysis. Through the modal analysis and find out the weak link of lathe bed and resonant frequency. In order to improve the dynamic characteristic of lathe bed, without changing job characteristics and difficult processing conditions, puts forward several improvement program, again on the proposed solution to the modal analysis. By contrast, determine the optimal structure of lathe bed improved scheme, for the structure design of lathe bed provides a theoretical basis.
\end{abstract}

\section{Introduction}

With the rapid development of numerical control technology, CNC grinding machine has been widely used, CNC grinding machine is not only to develop in the direction of high speed, high efficiency, high precision, but also more and more high to the requirement of reliability. Reliability refers to the product or system in its life cycle conditions, perform the desired function within a specified time period (no fault and within the specified performance). Grinding is usually the last link of the workpiece machining, so the precision of the grinding machine is the guarantee of processing quality of workpiece. [1] Due to the unbalanced structure, CNC grinding machine for high speed machine tools, bring the vibration of the grinding wheel at high speed will decrease the reliability of the machine tool. Therefore, dynamic characteristics analysis of CNC machine tools is necessary, especially in machine tool lathe bed base components. Lathe bed is mainly used for supporting the workbench, plate and wheel frame, grinding wheel rack base frame key parts and components, such as the stand or fall of its dynamic characteristics directly affect the machining accuracy of machine tool and the service life.

Modal analysis is a kind of common structural dynamics analysis of the types, it is harmonic response, response spectrum and transient dynamics analysis of the foundation. Modal analysis is mainly used in the study of the structure of the natural frequency and vibration mode, has nothing to do with the load and motion. Through the study of the modal analysis to find out the structure of lathe bed of the weak links and resonance frequency, provide the basis for structure design and improvement.[2] Structure improvement for machine tools at home and abroad tend to consider the increase of each order natural frequency, and did not consider the effects of structural changes after, structure to improve quality of lathe bed directly affect the manufacturing difficulty and cost. [3]With the improvement of accuracy of finite element analysis software and function, the analysis of machine tool more and more by finite element software. Common finite element analysis software ANSYS and ABAQUS, MSC/NASTRAN, etc , they are able to do the structure of the linear and nonlinear dynamics, statics analysis. This article uses ANSYS Workbench of lathe bed modal analysis. 


\section{Modal analysis basic theory}

Lathe bed is a multidimensional elastic vibration system, applied to all kinds of exciting force of the system is to make the power source of the lathe bed produce complex vibration. For $\mathrm{N}$ degrees of freedom damping vibration system, the basic vibration equation can be represented as:

$$
[M]\{\ddot{X}\}+[C]\{\dot{X}\}+[K]\{X\}=\{F\}
$$

Where $[M]=$ Stiffness matrix; $[C]=$ Dmping matrix; $[K]=$ Mass matrix;[F]= Outside stimulation matrix; $\ddot{X}$ =Acceleration matrix; $\dot{X}=$ Speed of matrix; $X=$ Displacement matrix. When ignore damping vibration system of the relationship between vibration angular frequency and vibration mode can be expressed as follows:

$$
\left([K]-W_{i}^{2}[M]\right)\left\{\varphi_{i}\right\}=0
$$

Solution of this equation can get the first order natural frequency is:

$$
f_{i}=\sqrt{\frac{k_{i}}{m_{i}}}(i=1,2, \ldots, \mathrm{n})
$$

\section{Modal analysis of lathe bed}

In the process of modal analysis need to set the material properties including material young's modulus, poisson's ratio and density.The boundary conditions should be set according to the actual structure of the state.[4]

Considering the lathe bed structure is extremely complex, if the modal analysis by finite element software directly, not only bring the analysis process difficulty may not be able to get the results, even in geometric modeling process was carried out on the bed structure is simplified, remove the little round hole, chamfering, little influence on the result of the analysis of structure Angle, etc. Using Pro/E to geometric modeling of lathe bed, its simplified geometric model as shown in figure 1 (a). IGES format among geometric model can be converted to import the ANSYS Workbench, using Modal Modal analysis module. First set material type, lathe bed casting, material for HT300, young's modulus of $1.43 \times 1011 \mathrm{n} / \mathrm{m} 2$, poisson's ratio of 0.27 , the density is $7300 \mathrm{~kg} / \mathrm{m} 3$. In the process of finite element analysis, meshing quality directly affect the results of the analysis, as a result of the meshing function of the ANSYS Workbench has strong. In the meshing principles under the premise of using automatic meshing. The result was a finite element model of as shown in figure 1(b), by 169150 nodes, 88991 units. Lathe bed is fixed in eight shim, so on lathe bed and pad iron from fixed constraints imposed rectangular plane, limit lathe bed six degrees of freedom. Considering the shim is not a part of the lathe bed, ANSYS Workbench is used in the analysis process of imprint mark rectangular piece of projection to the lathe bed base, constraint location is shown in figure 2 .

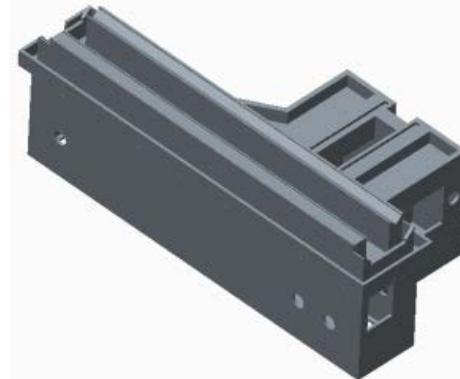

(a)

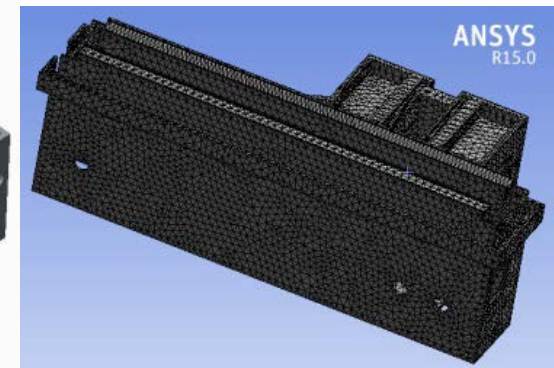

(b)

Fig. 1 Simplified geometric model and finite element model of lathe bed 


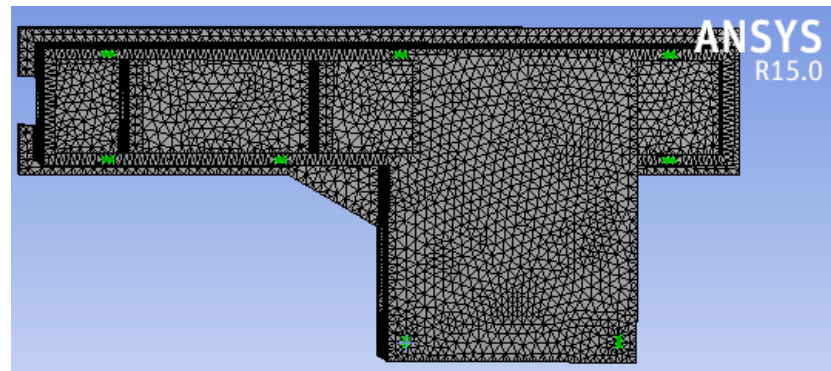

Fig. 2 A lathe bed constraints

Lathe bed is a have an unlimited number of degrees of freedom vibration system, there is an unlimited number of natural frequencies and corresponding to an unlimited number of vibration mode. The higher the vibration mode, in general, the higher the damping, role in vibration. In the process of machine tool vibration in low order modal have bigger influence on the workpiece processing quality, basic determines the dynamic characteristic of the machine tool, so here is only right before bed 6 order modal analysis, finite element analysis of the vibration mode diagram as shown in figure 3. Through modal figure deformation factor of amplification and animation simulation shows lathe bed of every order mode as shown in table 1.

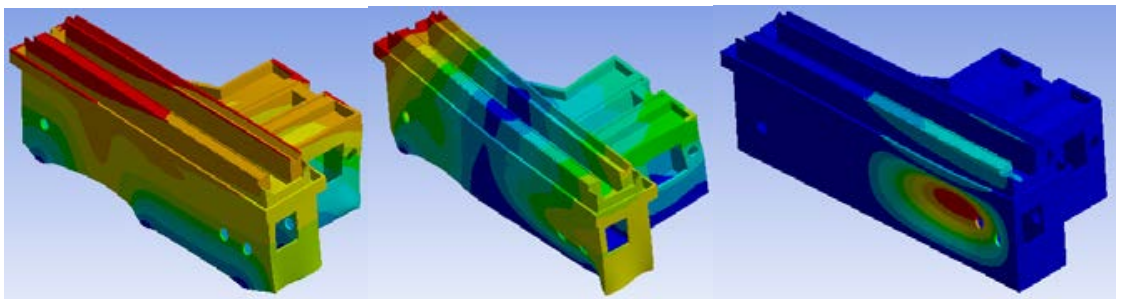

(a) the first order (b) the second order (c) the third order
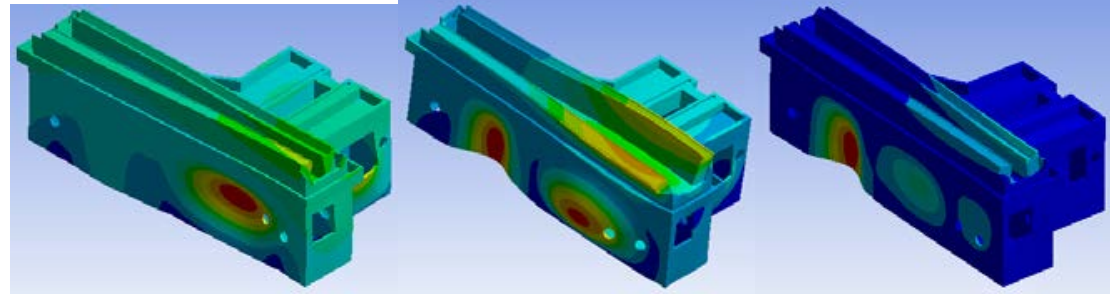

(d) the fourth order (e) the fifth order (f) the sixth order

Fig. 3 Bed before 6 order modal vibration mode

Table 1 Lathe bed of the inherent frequency and vibration mode

\begin{tabular}{ccc}
\hline $\begin{array}{c}\text { Order } \\
\text { number }\end{array}$ & $\begin{array}{c}\text { Natural } \\
\text { frequency }(\mathrm{Hz})\end{array}$ & Vibration mode \\
\hline 1 & 108.52 & $\begin{array}{c}\text { About the overall bending } \\
2\end{array}$ \\
3 & 156.64 & Around the $\mathrm{z}$ axis twisting as a whole \\
4 & 204.21 & Guide rail, both inside and outside bend \\
5 & 223.88 & Guide inside and outside bend, the before and after bending \\
6 & 248.37 & Guide both inside and outside bend, left wall wavy curve \\
\hline
\end{tabular}

From figure 3, the left wall of the lathe bed is the weak link, deformation, the main reason is that bed wall thickness is too thin. Table 1 illustrates the lathe bed. 4, 5, and 6 order modal vibration mode guide are substantial, both inside and outside bend, and guide the workbench function positioning and orientation of the main, and machining of bending in the guideway workbench to bring a lot of errors.

\section{Structure of lathe bed}

Through the above analysis, the left wall of the lathe bed is the weak link, the bed structure improvement is to improve the dynamic stiffness of the left wall. Improvement of lathe bed structure should not only consider the dynamic characteristics of lathe bed, good or bad, should also pay attention to the following three points: 1) the improved lathe bed working properties unchanged; 2) 
considering the lathe bed is cast, the improved lathe bed of the difficulty of casting process increase shoulds not be too large; 3) on the basis of the reasonable cost control to improve the lathe bed. The improvements of lathe bed structure mainly include: increase the wall thickness, increasing the number of stiffened plate, the reasonable arrangement of reinforcement plate location. In the face of this improvement project of three respectively analysis:

One way, by increasing the lathe bed of wall thickness to improve the dynamic characteristics of lathe bed. Considering the left wall on the lathe bed lathe bed vibration deformation is larger, for the convenience of the improved contrast, take a left wall thickness increases $8 \mathrm{~mm}$, B about wall thickness increased $4 \mathrm{~mm}$ respectively, $\mathrm{C}$ left wall thickness increase $6 \mathrm{~mm}$, right wall thickness increase $2 \mathrm{~mm}$. Will the improved lathe bed using the same steps to modal analysis, the results are shown in table 2.[5]

Table 2 Increase wall thickness bed after each order natural frequency and quality

\begin{tabular}{ccccccccc}
\hline \multicolumn{2}{l}{ Order number } & $\mathbf{1}$ & $\mathbf{2}$ & $\mathbf{3}$ & $\mathbf{4}$ & $\mathbf{5}$ & $\mathbf{6}$ & Quality/kg \\
\hline a & Natural & 110.45 & 159.98 & 226.66 & 243.12 & 266.18 & 287.3 & 2220.1 \\
b & frequenc & 111.16 & 160.93 & 221.25 & 239.66 & 265.09 & 277.42 & 2217.7 \\
c & y (Hz) & 110.92 & 160.65 & 224.93 & 241.71 & 265.91 & 282.02 & 2218.9 \\
\hline
\end{tabular}

The table 2 shows that by increasing the wall thickness lathe bed each order natural frequency were increased, the quality is almost the same conditions, in addition to the first two order frequencies increase left wall thickness increase the rest of each order frequency is greater than the increase right wall thickness. The figure 4 shows that after the fourth order frequency of the lathe bed is strongly influenced by the left wall, and in consideration of lathe bed after three order natural frequency of the workpiece machining accuracy of impact is bigger, so the improvement of lathe bed structure to increase the left wall thickness is better than the right to increase wall thickness.

Scheme 2, by increasing the number of stiffened plate to improve the dynamic characteristics of lathe bed. The increase of steel plate number will bring bed processing difficulties, therefore, stiffened plates should not be increased too much and the stiffened plate structure should not be complicated. Steel plate should be added in the region of the lathe bed weak, figure 4 illustrates the left wall two red area, deformation is greatly weak area, steel plate should be added in the red areas. As compared with plan a, respectively adopt $d$ bed side behind the weak area and thickness of $50 \mathrm{~mm}$ steel plate, e bed front-end weak area, stiffened plates with thickness of $50 \mathrm{~mm} \mathrm{f}$ bed two weak area and thickness of $25 \mathrm{~mm}$ steel plate respectively. Using the same method as above to the modal analysis, the results as shown in table 3.

Table 3 Bed adding reinforcement plate to each order natural frequency and quality

\begin{tabular}{ccccccccc}
\hline \multicolumn{2}{l}{ Order number } & 1 & 2 & 3 & 4 & 5 & 6 & $\begin{array}{c}\text { Quality/k } \\
\text { g }\end{array}$ \\
\hline a & Natural & 109.07 & 156.51 & 204.57 & 223.1 & 251.54 & 267.12 & 2215 \\
b & frequenc & 115.69 & 165.83 & 224.56 & 261.63 & 267.59 & 279.18 & 2215 \\
c & y (Hz) & 115.14 & 164.66 & 224.37 & 263.36 & 277.02 & 289.44 & 2215 \\
\hline
\end{tabular}

The table 3 shows that in the lathe bed weak areas or natural frequencies increase steel plate also has a corresponding increase, especially in both weak area stiffened plate after three order natural frequency increase significantly. Through frequency in table 3 and table 2 shows that under the condition of almost the same quality, stiffened plate respectively on two weak area than the increase in bed thickness scope of natural frequency increase significantly.

Plan 3, through the reasonable arrangement of reinforcement plate location to improve the dynamic characteristics of lathe bed. The figure 3 shows that placement of stiffened plates of lathe bed two is not uniform, uniform of stiffened plates can be decorated in the lathe bed 1/3, 2/3 the length of the place. Also to test modal analysis, the results of the analysis as shown in table 4 .

Table 4 Reasonable decorate stiffened plate position bed each order natural frequency

\begin{tabular}{ccccccc}
\hline Order number & 1 & 2 & 3 & 4 & 5 & 6 \\
\hline Natural frequency $(\mathrm{Hz})$ & 115.82 & 155.01 & 219.89 & 236.07 & 248.21 & 263.61 \\
\hline
\end{tabular}

By table 4, the uniform arrangement of the position of the steel plate on the lathe bed length direction, lathe bed in addition to the outside of the second order and the fifth order natural frequency 
slightly reduced the rest of the fourth order were increased, so the reinforcement plate location uniform distribution can also as a way to improve the dynamic characteristics of lathe bed.

Integrated the above three options, use add lathe bed wall thickness to improve the effect of lathe bed dynamic performance is inferior to increase the number of stiffened plate, and through reasonable arrangement of reinforcement plate location under the premise of without any increase in body weight can improve the dynamic performance of lathe bed to a certain extent. Considering the increasing number of stiffened plate can bring certain difficulty to manufacture of lathe bed, so the three schemes can be combined to improve the dynamic performance of lathe bed. Increase the left wall thickness of lathe bed $6 \mathrm{~mm}$, and Right increase $2 \mathrm{~mm}$ wall thickness, adding two steel plate thickness of $50 \mathrm{~mm}$ and uniform distribution on the lathe bed length direction, according to the above the same steps modal analysis, the result as shown in table 5.

Table 5 Comprehensive improvement of lathe bed after each order natural frequency

\begin{tabular}{ccccccc}
\hline Order number & 1 & 2 & 3 & 4 & 5 & 6 \\
\hline Natural frequency $(\mathrm{Hz})$ & 131.18 & 171.88 & 241.1 & 265.66 & 288.43 & 291.76 \\
\hline
\end{tabular}

The table 5 shows that the comprehensive improvement of lathe bed after each order natural frequency has a large range, the first order natural frequency is increased by $20.9 \%$ than before improvement, this method combines the advantages of the three kinds of solutions, can be used as a lathe bed structure to improve the final plan.

\section{Conclusion}

Workpiece machining quality mainly depends on the accuracy of machine tool, and the precision of the machine is mainly by the processing precision of parts and assembly accuracy and dynamic characteristics. Lathe bed support as the basis of machine tool parts, the characteristics of the dynamic characteristics of machine tool plays a key role. Through the study of the finite element analysis of CNC grinder lathe bed, find the weak link and resonant frequency. Given the current structure of machine tool parts mainly focus on improving each order natural frequency and did not consider adverse effect brought by the structural change, the author based on this, advances several improvement scheme, these schemes is without any increase in bed processing difficulty is increased (or not) and shall not affect the lathe bed work conducted on the basis of the improved. Finite element analysis for the improved lathe bed, through the analysis of modal frequency comparison, found the best solution in this scheme. Improved lathe bed each order natural frequency has great range, provides a theoretical basis not only for the structure design of lathe bed, have improved the structure of machine tools and various machine parts and components have important guiding significance. Improved lathe bed each order natural frequency has great range, provides a theoretical basis not only for the structure design of lathe bed, and improved structure of machine tools and various machine parts and components have important guiding significance.

\section{References}

[1] Michael g. Pecht , Kailash c. Kapur, conray, etc. Reliability engineering foundation [M]. Beijing: electronic industry press, 2011.

[2] Jiang Qiong . MKQ8312 CNC camshaft grinding machine dynamic performance analysis and structure improvement research [D]. Hunan: hunan university. 2007.

[3] Wu Min Xie Longhan. ANSYS Workbench finite element analysis and the simulation [M]. Beijing: electronic industry press, 2014.

[4] shiningray Zhong Jianlin. Based on the ANSYS Workbench bed material analysis of the impact of machine tool dynamic characteristics [J]. Journal of combination machine tools and automatic processing technology, 2015, (2) : 61-64.

[5] Zhang Xianglei, Bosch, yao Gang iron is strong, etc. Five axis nc grinding machine lathe bed structure analysis and optimization [J]. Journal of machine tools and hydraulic, 2012, 40 (15) : 18-22. 